\title{
PROJECT MANAGEMENT IN HEALTH AND MEDICAL RESEARCH
}

\author{
Carlos Bandeira de Mello Monteiro', Álvaro Dantas de Almeida Junior ${ }^{2}$, \\ Rubens Wajnzstejn ${ }^{3}$
}

A project manager is an individual who is able to apply knowledge, skills, tools and techniques to a broad range of activities in order to meet the requirements of a particular project, according to PMBOK $(2008)^{1}$ project manager is the person assigned by the performing organization to achieve the project objectives. However, within the area of health and medical research today (mainly in Brazil), it has become strikingly apparent that there is a lack of professional project management in the management of scientific projects. Despite the many requests that funding agencies and research institutions receive for research projects, the manner in which the projects are organized still need improvement.

Payne et al. (2011) $)^{2}$ published a study about the experience of researchers with project management in health and medical research. The authors started that project management is widely used to deliver projects on time, within budget and of defined quality; however, there is little published information describing its use in managing health projects.

Despite a paucity of information about project management in health research, two factors must be presented and considered: (1) assessing performance, which includes cost, time, functionality and quality remain the important criteria for assessing performance of projects (Papke-Shields et al., 2010) ${ }^{3}$; (2) considering and properly using the various stages of a project, such as: analysis of logic; estimation of durations; calculation of project times; impact of resource limitations; adjustments to achieve project target; preparation of a working plan of action and updating during progress of the project (Woodward,1983) ${ }^{4}$.

It is difficult to say whether researchers in health care have the training and the knowledge of the criteria and project management stages, and that this knowledge is the major difference in scientific production. Thus, what is different of those researchers who can participate in large research groups and provide high productivity?

The answer is likely not in the knowledge of project management, but in the characteristics of these researchers as potential project managers. Hartman $(2008)^{5}$ conducted an interesting study identifying project managers that were regarded highly by peers, clients and other project stakeholders. These project managers were identified and were met with over a period of about 15 years. During that period, through discussion, a pattern emerged that supported a common set of attributes of these managers. These attributes, presented below, also appear to be the major difference between researchers with extensive scientific production and others.

1. All were able to instantly identify problems and their impact, could predict issues and challenges and be ready to deal with them

\footnotetext{
1 School of Arts, Sciences and Humanities, University of São Paulo, São Paulo, SP ,Brazil.

2 ICONE: Instituto de Cirurgia Ocular do Nordeste - Recife, Pernambuco, Brazil.

3 Department of Neurology, School of Medicine of ABC, Av. Príncipe de Gales, 821 09060-650 Santo Andre, SP, Brazil. Corresponding author:
}

Suggested citation: Monteiro CBM, Almeida Junior AD, Wajnzstejn R. Project Management in Health and Medical Research. Journal of 
effectively. Resulting decisions were generally considered sound;

2. All demonstrated exceptional skills in building and maintaining relationships. This was underpinned by good communication skills;

3. There was a high level of trust between the project manager and other stakeholders.

If this assumption is correct and researchers with high productivity whose main characteristics are the same as those displayed by the highly regarded project managers, there very well could be growth in scientific production in Brazil with the proper training of project managers in scientific research. This will likely be important training for future researchers to be effective in their specialty areas.

A publication of scientific articles in the Journal of Human Growth and Development is an example of the completion of a research project. Projects from the authors Vanderlei FM, Vanderlei LCM, Barreto GS, Garner DM 6 (Risk appraisal by novel chaotic globals to HRV in subjects with malnutrition); Leone C, Nascimento VG, da Silva JPC, Bertoli CJ (Waist/ height ratio: a marker of nutritional alteration in preschool children) $)^{7}$ and Badaró FAR, Araújo RC, Behlau M (The Copenhagen neck functional disability scale - CNFDS: translation and cultural adaptation to brazilian portuguese $)^{8}$ are all successful examples of projects. They were conducted in different regions with different cultures and diverse approaches and offering the final product of the project, i.e., to be published and disseminated to peers in the language of science (English).

Thus the concerns of today in scientific productivity that relate to the variables of quantity and quality are resolved at the time the researchers (project managers) finalize the steps and enter their scientific contributions to international peer discussion, highlighting "The Logical Method to Scientific Writing" in the formal structuring, systematizing processes, decision on scientific writing in logical precepts of "doing science" and communication elements. First comes the solid product, then how to present it. The final product of the research project, branded as a success, is presented with logical argument, conclusions drawn from those assumptions and a method to include the dynamics of writing, if possible, transgressing the more regional science and becoming truly international. 


\section{REFERENCES}

1. PMBOK, A Guide to the project management body of knowledge (PMBOK Guide) - Forth Edition. Published by: Project Management Institute, INC, 2008.

2. Payne JM, France KE, Henley N, D\&apos; Antoine $H A$, Bartu AE, Elliott EJ, Bower C. Researchers\&apos; experience with project management in health and medical research: results from a post-project review. BMC Public Health, 2011; 2 (11):424.

3. Papke-Shields KE, Beise C, Quan J. Do project managers practice what they preach, and does it matter to project success? International Journal of Project Management, 2010; 28: 650662.

4. Woodward JF. Project management education levels of understanding and misunderstanding. The Project Manager. 1983; 1(3); 173-178.
5. Hartman F. Preparing the mind for dynamic management International Journal of Project Management. 2008; 26: 258-267.

6. Vanderlei FM, Vanderlei LCM, BarretoGS, Garner DM. Risk appraisal by novel chaotic globals to HRV in subjects with malnutrition. Journal of Human Growth and Development 2014;24(3):243-248.

7. Leone C, Nascimento VG, da Silva JPC, Bertoli CJ. Waist/height ratio: a marker of nutritional alteration in preschool children. Journal of Human Growth and Development 2014;24(3):289-294.

8. Badaró FAR, Araújo RC, Behlau M. The Copenhagen neck functional disability scale CNFDS: translation and cultural adaptation to brazilianportuguese. Journal of Human Growth and Development 2014;24(3): 304-312 
